\title{
Multisteroid LC-MS/MS assay for glucocorticoids and androgens and its application in Addison's disease
}

\section{Paal Methlie ${ }^{1,2}$, Steinar Hustad' ${ }^{1}$ Ralf Kellman², Bjørg Almås², Martina M Erichsen³, Eystein S Husebye ${ }^{1,3}$ and Kristian Løvås ${ }^{1,3}$}

${ }^{1}$ Department of Clinical Science, University of Bergen, N-5021 Bergen, Norway and ${ }^{2}$ The Hormone Laboratory ${ }^{3}$ Department of Medicine, Haukeland University Hospital, N-5021 Bergen, Norway

\section{Correspondence}

should be addressed

to P Methlie

Email

paal.methlie@med.uib.no

\begin{abstract}
Objective: Liquid chromatography-tandem mass spectrometry (LC-MS/MS) offers superior analytical specificity compared with immunoassays, but it is not available in many regions and hospitals due to expensive instrumentation and tedious sample preparation. Thus, we developed an automated, high-throughput LC-MS/MS assay for simultaneous quantification of ten endogenous and synthetic steroids targeting diseases of the hypothalamic-pituitary-adrenal axis and gonads.

Methods: Deuterated internal standards were added to $85 \mu \mathrm{l}$ serum and processed by liquid-liquid extraction. Cortisol, cortisone, prednisolone, prednisone, 11-deoxycortisol, dexamethasone, testosterone, androstenedione and progesterone were resolved by ultra-high-pressure chromatography on a reversed-phase column in $6.1 \mathrm{~min}$ and detected by triple-quadrupole mass spectrometry. The method was used to assess steroid profiles in women with Addison's disease (AD, $n=156)$ and blood donors (BDs, $n=102$ ).

Results: Precisions ranged from 4.5 to $10.1 \%$ relative standard deviations (RSD), accuracies from 95 to $108 \%$ and extraction recoveries from 60 to $84 \%$. The method was practically free of matrix effects and robust to individual differences in serum composition. Most postmenopausal AD women had extremely low androstenedione concentrations, below $0.14 \mathrm{nmol} / \mathrm{l}$, and median testosterone concentrations of $0.15 \mathrm{nmol} / \mathrm{l}$ (interquartile range $0.00-0.41)$, considerably lower than those of postmenopausal BDs $(1.28 \mathrm{nmol} / \mathrm{l}(0.96-1.64)$ and $0.65 \mathrm{nmol} / \mathrm{l}(0.56-1.10)$ respectively). AD women in fertile years had androstenedione concentrations of $1.18 \mathrm{nmol} / \mathrm{l}(0.71-1.76)$ and testosterone concentrations of $0.44 \mathrm{nmol} / \mathrm{l}$ (0.22-0.63), approximately half of those found in BDs of corresponding age.

Conclusion: This LC-MS/MS assay provides highly sensitive and specific assessments of glucocorticoids and androgens with low sample volumes and is suitable for endocrine laboratories and research. Its utility has been demonstrated in a large cohort of women with $A D$, and the data suggest that women with $A D$ are particularly androgen deficient after menopause.
\end{abstract}

\section{Key Words}

- liquid chromatography mass spectrometry

- androgens

- glucocorticoids

- adrenal insufficiency

- Addison's disease 


\section{Introduction}

Glucocorticoid and androgen hormone measurements play a decisive role in the diagnosis and management of many disorders of the hypothalamic-pituitary-adrenal (HPA) axis and gonads. Examples include Addison's disease (AD), Cushing's syndrome (CS) and congenital adrenal hyperplasia, male hypogonadism and female hyperandrogenism. Although immunoassays have largely been used to measure steroid hormones, over the last decade, mass spectrometry (MS) has increasingly been adopted as it offers superior analytical specificity and accuracy. However, MS is not commonly available to clinicians in many regions and hospitals. The high cost of MS instruments, lack of expertise, and cumbersome and time-consuming sample preparation procedures are factors likely to slow its adoption. The development of simple, reliable, and cost- and labour-efficient methods is, therefore, important.

Liquid chromatography coupled to tandem mass spectrometry (LC-MS/MS) is a highly selective mode of detection. It enables simultaneous determination of multiple steroids at very low concentrations in a single analytical run. Although many papers have been published on LC-MS/MS assays that measure one or a few steroid hormones, only few papers have reported methods that extensively exploit the capability of multiplex determination of steroids in human serum $(1,2,3)$. This strategy could simplify the laboratory set-up by eliminating the need to use numerous separate methods and make instrument utilization more efficient.

In MS/MS, the specificity is increased by collisioninduced fragmentation of the analyte into a molecular fingerprint that could be identified by monitoring two or more fragments. However, many previously published multisteroid LC-MS/MS assays monitor only one mass transition (collision fragment) per analyte $(2,3,4,5,6)$ and consequently have an increased risk of not detecting isobaric interference. Another analytical concern is that inter-individual differences in serum composition, such as lipids and binding proteins, could potentially impact measurements. This is often not investigated at all. Most published methods also require relatively large sample volumes to provide sufficient sensitivity $(1,2,4,7,8)$ and have long run times $(1,2,4,7)$.

The work-up and management of endocrine disorders commonly involve the administration of synthetic steroid hormones. The determination of synthetic glucocorticoids used in dynamic endocrine testing and pharmacological treatment may thus be a valuable supplement to the measurement of endogenous steroids. For example, the measurements of serum dexamethasone (DXM) could provide pharmacokinetic data useful in the evaluation of the DXM suppression test $(9,10)$, and therapeutic drug monitoring of prednisone and prednisolone has the potential to optimize treatment $(11,12)$. Because of the widespread use of these glucocorticoids and impact on endogenous cortisol levels, information on serum levels may also be valuable in the setting of a routine endocrine laboratory.

Therefore, the objective of this study was to develop a LC-MS/MS method that quantifies endogenous and synthetic glucocorticoid hormones as well as endogenous androgens. With a sample volume of only $85 \mu \mathrm{l}$ serum, the method provides a highly sensitive, fast, comprehensive and cost-effective evaluation of patients with a range of disorders related to glucocorticoid and androgen hormones. Its utility was demonstrated by comparing the steroid profiles of women with AD with those of healthy female blood donors (BDs). To our knowledge, this report is the first to investigate androgen levels in a large cohort of women with AD using highly specific MS.

\section{Materials and methods}

\section{Chemicals}

Cortisol, cortisone, prednisolone, prednisone, 11-deoxycortisol (11DOC), testosterone, androstenedione, $17 \alpha$-hydroxyprogesterone (17OHP) and progesterone were obtained from Steraloids, Inc. (Newport, RI, USA), and DXM was obtained from Alfa Aesar (Ward Hill, MA, USA).

The deuterated internal standards (ISs) cortisol-d4 (cortisol-9,11,12,12-d4, 97-98\% atom D), cortisone-d2 (4-pregnen-17 $\alpha, 21$-diol-3,11,20-trione-1,2-d2, >98\% atom D), prednisolone-d6 (1,4-pregnadien-11 $\beta, 17 \alpha, 21$-triol-3, 20-dione-2,4,6,6,21,21-d6, >98\% atom D), DXM-d4 (DXM-4,6 $\alpha, 21,21-\mathrm{d} 4$, 96-98\% atom D), 11DOC-d2 (4-pregnen-17 $\alpha, 21$-diol-3,20-dione-21,21-d2, >96\% atom D), testosterone-d3 (testosterone-16,16,17-d3, >98\% atom D), androstenedione-d7 (4-androsten-3,17-dione-2,2,4,6,6, 16,16-d7, >98\% atom D), 17OHP-d8 (4-pregnen-17 $\alpha$-ol-3, 20-dione-2,2,4,6,6,21,21,21-d8, >98\% atom D) and progesterone-d9 (progesterone-2-2-4-6-6-17 $\alpha, 21,21,21-\mathrm{d} 9$, $>98 \%$ atom D) were purchased from CDN Isotopes (Pointe-Claire, Quebec, Canada).

MS-grade acetonitrile (ACN), methanol $(\mathrm{MeOH})$, formic acid (>98\%) and ammonium formate (>98\%) were obtained from Merck. Milli-Q water purification

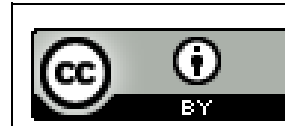

This work is licensed under a Creative Commons Attribution 3.0 Unported License. 
system (Millipore, Burlington, MA, USA) was used to prepare de-ionized water $(>18 \mathrm{M} \Omega \mathrm{cm})$. Dextran-coated charcoal (product number C6241) was obtained from Sigma-Aldrich.

\section{Calibrators, ISs and quality controls}

Steroid-free human serum was prepared with activated dextran-coated charcoal according to the manufacturer's protocol. Serum was obtained from healthy BDs.

All steroid hormones were separately dissolved in $\mathrm{MeOH}$ at concentrations of $3 \mathrm{mM}$ for the analytes and $500 \mu \mathrm{M}$ for the ISs. Two separate mixtures of the analytes and the ISs, designated standard substock and IS substock, were prepared in $\mathrm{MeOH}$. The standard substock contained each steroid hormone at a concentration 100 times that of the highest working calibrator. Working calibrators were prepared by serially diluting the standard substock $1: 4$ in $\mathrm{MeOH}$ and then by adding $2 \mathrm{ml}$ of each dilution to $198 \mathrm{ml}$ steroid-free serum. The final working calibrators covered the following measuring ranges: $1.95-2000 \mathrm{nmol} / \mathrm{l}$, cortisol; $0.98-250 \mathrm{nmol} / 1$, cortisone; $0.98-1000 \mathrm{nmol} / \mathrm{l}$, prednisolone; 0.98-1000 nmol/l, prednisone; 0.06-250 nmol/l, DXM; $\quad 0.10-25 \mathrm{nmol} / \mathrm{l}, \quad 11 \mathrm{DOC} ; \quad 0.02-75.0 \mathrm{nmol} / \mathrm{l}$, testosterone; $\quad 0.12-125 \mathrm{nmol} / 1$, androstenedione; 0.24-250 nmol/l, 17OHP; 0.24-250 nmol/1, progesterone; and a blank control. Six calibrators were used for all the analytes, except for cortisone and 11DOC (five calibrators) and testosterone and DXM (seven calibrators).

The concentrations of each of the ISs in the IS substock were 100 times that of the working IS solution. The working IS solution was prepared by diluting the IS substock with $\mathrm{H}_{2} \mathrm{O}: \mathrm{MeOH}$ (1:1). The final working IS solution contained $850 \mathrm{nmol} / 1$ cortisol-d4, $850 \mathrm{nmol} / 1$ cortisone-d2, $425 \mathrm{nmol} / 1$ prednisolone-d6, $106 \mathrm{nmol} / \mathrm{l}$ DXM-d4, $128 \mathrm{nmol} / 1$ 11DOC-d2, $51.0 \mathrm{nmol} / 1$ androstenedione-d7, $31.9 \mathrm{nmol} / 1$ testosterone-d3, $106 \mathrm{nmol} / \mathrm{l}$ 17OHP-d8 and $106 \mathrm{nmol} / \mathrm{l}$ progesterone-d9.

Quality controls (QCs) were prepared in steroid-free serum at three levels (low, medium and high) by adding each steroid hormone to a final concentration corresponding to $0.30,5.0$ and $50 \%$ of the highest working standard. All standards, calibrators and QCs were stored in Nunc cryovials (Nalge Nunc International, Roskilde, Denmark) at $-80^{\circ} \mathrm{C}$

\section{Sample preparation procedure}

To $85 \mu$ l of serum, working calibrators or QCs, $10 \mu \mathrm{l}$ of an IS were added, mixed and equilibrated for $1 \mathrm{~h}$. The steroid hormones were then extracted with $825 \mu$ l ethyl acetate: hexane $(80: 20)$. The supernatant $(600 \mu \mathrm{l})$ was transferred to a new vial and washed with $50 \mu \mathrm{l}$ ammonium formate buffer (pH 9.0, 0.1 M). Subsequently, $500 \mu \mathrm{l}$ of organic phase were transferred to a new vial and evaporated at $50{ }^{\circ} \mathrm{C}$ for 25 min under $\mathrm{N}_{2}$ flow and finally reconstituted in $50 \mu \mathrm{H}_{2} \mathrm{O}$ :formic acid:MeOH (49.9:0.1:50). Sample preparation was automated on a Hamilton Star (Hamilton Robotics, Inc., Reno, NV, USA) using exclusively $1.1 \mathrm{ml}$ glass vials. Mixing steps were performed by repeated pipette aspiration/dispense cycles. Centrifugation was not necessary because the aquatic and organic phases separated within minutes.

\section{LC-MS/MS conditions}

An Agilent 1290 UPLC system (Santa Clara, CA, USA) equipped with a thermostated autosampler $\left(4^{\circ} \mathrm{C}\right)$ and a degasser was used for chromatographic separation. Processed serum $(5 \mu \mathrm{l})$ was separated over a Zorbax RRHD C18 reversed-phase column $(50 \times 2.1 \mathrm{~mm}, 1.8 \mu \mathrm{m}$ particle size, Agilent) maintained at $30{ }^{\circ} \mathrm{C}$. The mobile phases were water (A) and ACN (B) with $0.1 \%$ formic acid. The column was developed with stepwise linear gradient elution according to the following timetable: $0.00 \mathrm{~min}$, $15 \%$ B; $0.25 \mathrm{~min}, 15 \%$ B; $0.50 \mathrm{~min}, 25 \% \mathrm{~B} ; 1.70 \mathrm{~min}, 28.5 \% \mathrm{~B}$; $3.80 \mathrm{~min}, 40 \% \mathrm{~B} ; 4.20 \mathrm{~min}, 50 \% \mathrm{~B} ; 4.90 \mathrm{~min}, 70 \% \mathrm{~B} ; 5.00 \mathrm{~min}$, $95 \% \mathrm{~B} ; 5.50 \mathrm{~min}, 95 \% \mathrm{~B} ; 5.60 \mathrm{~min}, 15 \% \mathrm{~B}$; and $6.10 \mathrm{~min}$, $15 \% \mathrm{~B}$. Flow rate was $1000 \mu \mathrm{l} / \mathrm{min}$ and the column effluent was delivered to the mass spectrometer in the time window 1.1-5.0 min.

The LC system was coupled to an Applied Biosystems/MDS SCIEX API 5500 triple-quadrupole mass spectrometer operating with electrospray ionization (Applied Biosystems/MDS, Foster City, CA, USA). Manual tuning and selection of mass transitions were performed using a $\mathrm{T}$-split to mix the $5 \mu \mathrm{l} / \mathrm{min}$ infusion containing $500 \mathrm{nmol} / \mathrm{l}$ of the compound with the $1000 \mu \mathrm{l} / \mathrm{min}$ mobile phase flow (35\% B). Using this set-up, additional Q1 and Q3 scans (90-500 $\mathrm{m} / \mathrm{z}$ ) were performed by varying the ion source parameters (voltage, temperature and gas flows) to investigate the stability of the substances under conservative and extreme conditions, as well as the formation of adducts. Ion source parameters and mass transitions are reported in Table 1. Entrance potential was $10 \mathrm{~V}$, collision gas was set to medium and resolution was set to unit for Q1 and Q3. To increase scan time for each analyte, the multiple reaction monitoring (MRM) was divided into seven periods based on the time of elution. All hardware was managed using the Analyst Software (version 1.5.1; Applied Biosystems/MDS).

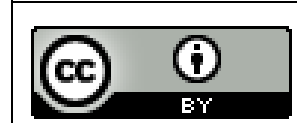

This work is licensed under a Creative Commons Attribution 3.0 Unported License. 
Table 1 MRM transitions and compound-dependent parameters.

\begin{tabular}{|c|c|c|c|c|c|c|c|c|c|c|c|c|}
\hline \multirow[b]{3}{*}{ Period } & \multicolumn{6}{|c|}{ Quantifier } & \multicolumn{6}{|c|}{ Qualifier } \\
\hline & \multicolumn{2}{|c|}{ MRM transition } & \multirow{2}{*}{$\begin{array}{c}\begin{array}{c}\text { Dwell } \\
\text { time }\end{array} \\
\text { (ms) }\end{array}$} & \multirow{2}{*}{$\begin{array}{l}\text { DP } \\
(\mathrm{V})\end{array}$} & \multirow{2}{*}{$\begin{array}{l}\mathrm{CE} \\
(\mathrm{V})\end{array}$} & \multirow{2}{*}{$\begin{array}{l}\text { CXP } \\
(V)\end{array}$} & \multicolumn{2}{|c|}{ MRM transition } & \multirow{2}{*}{$\begin{array}{c}\begin{array}{c}\text { Dwell } \\
\text { time }\end{array} \\
\text { (ms) }\end{array}$} & \multirow{2}{*}{$\begin{array}{l}\text { DP } \\
(\mathrm{V})\end{array}$} & \multirow{2}{*}{$\begin{array}{l}\mathrm{CE} \\
(\mathrm{V})\end{array}$} & \multirow{2}{*}{$\begin{array}{l}\text { CXP } \\
\text { (V) }\end{array}$} \\
\hline & Q1 & Q3 & & & & & Q1 & Q3 & & & & \\
\hline \multicolumn{13}{|l|}{1} \\
\hline Cortisol & 407.2 & 297.0 & 35 & -50 & -42 & -23 & 407.2 & 282.0 & 10 & -50 & -49 & -23 \\
\hline Cortisol-d4 & 411.4 & 301.1 & 35 & -50 & -45 & -23 & 411.4 & 286.1 & 10 & -50 & -48 & -23 \\
\hline Prednisolone & 405.2 & 295.0 & 35 & -50 & -42 & -23 & 405.2 & 280.0 & 10 & -50 & -48 & -23 \\
\hline Prednisolone-d6 & 411.3 & 333.2 & 35 & -50 & -23 & -23 & 411.3 & 284.1 & 10 & -50 & -48 & -23 \\
\hline Prednisone & 403.3 & 299.1 & 35 & -50 & -25 & -23 & 403.3 & 285.1 & 10 & -50 & -40 & -23 \\
\hline Cortisone & 405.3 & 301.1 & 35 & -50 & -26 & -23 & 405.3 & 311.1 & 10 & -50 & -41 & -23 \\
\hline Cortisone-d2 & 407.3 & 303.1 & 35 & -50 & -28 & -23 & 407.3 & 313.0 & 10 & -50 & -41 & -23 \\
\hline \multicolumn{13}{|l|}{2} \\
\hline DXM & 437.4 & 361.1 & 80 & -80 & -24 & -24 & 437.4 & 307.1 & 80 & -80 & -42 & -15 \\
\hline DXM-d4 & 441.3 & 309.0 & 80 & -80 & -42 & -20 & 441.3 & 363.2 & 80 & -80 & -24 & -24 \\
\hline \multicolumn{13}{|l|}{3} \\
\hline 11DOC & 347.2 & 96.9 & 80 & 50 & 30 & 12 & 347.1 & 108.9 & 80 & 50 & 31 & 12 \\
\hline $11 \mathrm{DOC}-\mathrm{d} 2$ & 349.3 & 108.9 & 80 & 50 & 33 & 12 & 349.3 & 96.9 & 80 & 50 & 30 & 12 \\
\hline \multicolumn{13}{|l|}{4} \\
\hline Testosterone & 289.2 & 97.0 & 80 & 85 & 30 & 12 & 289.2 & 109.0 & 80 & 85 & 33 & 12 \\
\hline Testosterone-d3 & 292.2 & 109.0 & 80 & 91 & 35 & 12 & 292.2 & 97.0 & 80 & 91 & 33 & 12 \\
\hline \multicolumn{13}{|l|}{5} \\
\hline Androstenedione & 287.2 & 96.9 & 60 & 105 & 30 & 16 & 287.2 & 108.9 & 60 & 105 & 33 & 15 \\
\hline Androstenedione-d7 & 294.1 & 99.7 & 60 & 116 & 29 & 16 & 294.1 & 113.0 & 60 & 116 & 35 & 15 \\
\hline \multicolumn{13}{|l|}{6} \\
\hline $17 \mathrm{OHP}$ & 331.3 & 96.9 & 60 & 88 & 30 & 10 & 331.3 & 108.9 & 60 & 88 & 34 & 14 \\
\hline 17OHP-d8 & 339.2 & 100.0 & 60 & 106 & 33 & 16 & 339.2 & 113.1 & 60 & 106 & 41 & 12 \\
\hline \multicolumn{13}{|l|}{7} \\
\hline Progesterone & 315.3 & 96.9 & 35 & 95 & 30 & 12 & 315.3 & 108.9 & 35 & 95 & 28 & 12 \\
\hline Progesterone-d9 & 324.2 & 100.2 & 35 & 110 & 37 & 12 & 324.2 & 113.0 & 35 & 110 & 27 & 12 \\
\hline
\end{tabular}

DP, declustering potential; CE, collision energy; CXP, collision exit potential; 11DoC, 11-deoxycortisol; DXM, dexamethasone; $17 \mathrm{OHP}, 17 \alpha$-hydroxyprogesterone.

\section{Quantification and QC}

Quantification was based on peak area ratios of the analyte to the corresponding IS. Standard curves were computed using a linear least-squares regression analysis with $1 / \mathrm{x}$ or $1 / \mathrm{x}^{2}$ weighting to assign priority to the lower range of the calibration curves.

To accept analytical runs, the back-calculated concentrations of at least $80 \%$ of the working calibrators had to be within $\pm 15 \%$ (20\% for the lowest calibrator) of their nominal concentration. Two sets of QCs (low, medium and high) were run in each batch (96 samples). The measured concentrations of at least one QC at each level and at least $75 \%$ of all the QCs were required to be within $\pm 15 \%$ their nominal levels. Interference was suspected if the peak area ratio of quantifier to qualifier transitions deviated more than $\pm 40 \%$ from the corresponding ratio of the third highest calibrator.

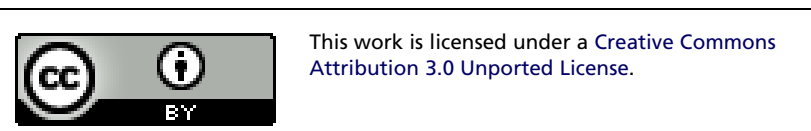




\section{Method validation}

Within-day and between-day precisions were investigated at three levels by running the QCs in replicates $(n=6)$ on 12 different days. The coefficients of variance $(\mathrm{CV})$ were calculated using one-way ANOVA. Accuracy (\%) was computed as (measured concentration/nominal concentration) $\times 100$, using the means of all the measured concentrations. The method was also compared with immunoassays using the Passing-Bablok regression and Bland-Altman plots.

The limits of detection (LoDs) and lower limits of quantification (LLoQs) were determined by adding the analytes at progressively lower levels to steroid-free serum and analysing samples in replicates $(n=6)$. The LoD was defined as the concentration with a signal-to-noise ratio above 3 and the LLoQ as the lowest concentration with a CV below $20 \%$ and accuracy within $\pm 20 \%$.

Recovery, matrix effects (MEs) and linearity were investigated in charcoal-stripped serum obtained from different individuals, adopting the principles suggested by Matuszewski et al. (13). Analytes were added to steroid-free serum obtained from six individuals; aliquots of each serum were spiked to six levels corresponding to the working standards. Duplicate sera were spiked both before extraction (pre-extract spike) and after evaporation (postextract spike) by adding $20 \mu \mathrm{l}$ of the standard substock per $980 \mu \mathrm{l}$ serum. Moreover, analytes were added to a 'blank' reconstitution solvent (reference). Reference samples were analysed immediately before, in the middle and after the pre/post-spike series. Extraction recoveries (ERs), ionsource-related MEs and overall process efficiency (PE) were calculated from the mean of duplicate samples according to the formulas given in Supplementary Table 1, see section on supplementary data given at the end of this article. Evaporation of the organic phase during sample preparation was closely monitored by gravimetric measurements of simultaneously run control samples, and ERs, MEs and PE were adjusted accordingly.

Linearity was evaluated based on residual plots and correlation coefficients. Relative MEs (14), that is, the impact of inter-individual differences in serum composition, were assessed by computing the slope constant based on each of the six pre-extraction spiked sera from the recovery experiment. The slope constants were derived from weighted $\left(1 / \mathrm{x}\right.$ or $\left.1 / \mathrm{x}^{2}\right)$ least-squares linear regression of nominal concentration vs analyte:IS peak area ratio.

All analytes and ISs and other potentially interfering steroid hormones (Supplementary Table 2, see section on supplementary data given at the end of this article) were prepared separately in water at concentrations of $2000 \mathrm{nmol} / \mathrm{l}$. These included all drugs containing steroid hormones that are commercially available in Norway. We also reviewed data from random samples received at the Hormone Laboratory $(n=926)$, from rheumatic patients on prednisolone therapy $(n=50)$ and from patients taking DXM $(n=25)$ for interfering peaks and deviations of the quantifier:qualifier peak area ratio.

Stability was investigated by computing the mean of triplet analysis of QCs at three concentration levels after storage under different conditions. Stability was examined after storage at ambient temperature for 1, 2, 4, 8, 24 and $96 \mathrm{~h}$, in a refrigerator $\left(4^{\circ} \mathrm{C}\right)$ for $1,2,5,10,20$ and 30 days, and in a freezer $\left(-20^{\circ} \mathrm{C}\right)$ for 1,2 and 3 months. Freezethaw stability was determined after five cycles of freezing to $-80^{\circ} \mathrm{C}$. The stability of the processed samples $(n=96)$ in the autosampler was studied by repeatedly analysing the same batch on 4 consecutive days.

\section{Application: steroid profiles of women with AD and BDs}

The method was applied to samples obtained from the Norwegian registry of organ-specific autoimmune diseases. The study population has been described previously (15), and sera obtained from women with $\mathrm{AD}$ $(n=156)$ and female BDs $(n=102)$ were analysed. The Regional Committee for Medical Ethics of Western Norway and the National Data Inspectorate approved the study. All of the patients gave written informed consent after complete explanation of the purpose and nature of all the procedures used. Most of the AD patients were on cortisone acetate replacement therapy, but five were using prednisolone. Ten patients had premature ovarian failure and seven were on DHEA replacement therapy. Blood samples were drawn between 0800 and $1600 \mathrm{~h}$. For statistical analyses, the subjects were stratified into three groups: young ( $<40$ years), middle aged ( $40-60$ years) and old ( $>60$ years). The groups were compared by the Kruskal-Wallis test using the Wilcoxon test as a post hoc analysis, and Bonferroni-adjusted $P$ values are reported. $P<0.05$ was considered statistically significant.

\section{Results}

\section{Precision, accuracy, lower limit of detection and quantification}

Data from the precision and accuracy experiments are reported in Table 2 . Total $\mathrm{CV}$ were $\leq 10.1 \%$ for all the

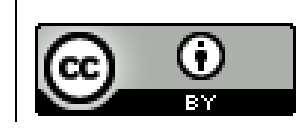


Table 2 Precision and accuracy.

\begin{tabular}{|c|c|c|c|c|c|c|c|c|c|c|}
\hline & Cortisol & Cortisone & Prednisolone & Prednisone & DXM & 11DOC & Testosterone & $\begin{array}{c}\text { Andro- } \\
\text { stenedione }\end{array}$ & 170HP & $\begin{array}{c}\text { Pro- } \\
\text { gesterone }\end{array}$ \\
\hline \multicolumn{11}{|l|}{ QC 1} \\
\hline Mean & 5.80 & 3.01 & 2.96 & 3.05 & 0.747 & 0.305 & 0.223 & 0.372 & 0.757 & 0.736 \\
\hline Within-day CV (\%) & 5.8 & 6.8 & 7.7 & 7.2 & 4.3 & 8.6 & 4.6 & 9.3 & 7.1 & 7.0 \\
\hline Total CV (\%) & 7.4 & 6.9 & 10.1 & 9.8 & 5.1 & 9.7 & 5.2 & 9.3 & 9.8 & 8.4 \\
\hline Accuracy (\%) & 97 & 100 & 99 & 102 & 100 & 102 & 99 & 99 & 101 & 98 \\
\hline \multicolumn{11}{|l|}{ QC 2} \\
\hline Mean & 101 & 50.4 & 51.3 & 53.8 & 12.5 & 5.00 & 3.71 & 6.10 & 12.2 & 12.5 \\
\hline Within-day CV (\%) & 3.0 & 3.9 & 4.3 & 3.8 & 3.7 & 4.7 & 5.1 & 3.9 & 4.5 & 6.1 \\
\hline Total CV (\%) & 4.5 & 4.7 & 5.3 & 8.7 & 4.8 & 5.7 & 5.6 & 5.0 & 7.7 & 6.9 \\
\hline Accuracy (\%) & 101 & 101 & 103 & 108 & 100 & 100 & 99 & 98 & 98 & 100 \\
\hline \multicolumn{11}{|l|}{ QC 3} \\
\hline Mean & 1004 & - & 517 & 535 & 128 & - & 36.4 & 61.6 & 121 & 118 \\
\hline Within-day CV (\%) & 4.7 & - & 5.0 & 4.7 & 4.0 & - & 4.7 & 4.1 & 4.6 & 4.5 \\
\hline Total CV (\%) & 5.7 & - & 5.5 & 8.8 & 5.2 & - & 4.9 & 5.0 & 8.0 & 6.8 \\
\hline Accuracy (\%) & 100 & - & 103 & 107 & 102 & - & 97 & 99 & 96 & 95 \\
\hline
\end{tabular}

QCs were run in replicates of 6 on 12 different days. Total CV includes within-day and between-day variability. All concentrations are reported as nmol/l. OC 3 levels of cortisone and 11DOC are above the upper limit of quantification and thus omitted. CV, coefficient of correlation; 11DOC, 11-deoxycortisol; DXM, dexamethasone; $170 \mathrm{HP}, 17 \alpha$-hydroxyprogesterone.

compounds, and accuracies were in the range of $95-108 \%$. The LoDs and LLoQs are reported in Table 3, and chromatograms of the lowest calibrators are shown in Fig. 1. Comparison of the LC-MS/MS method with immunoassays available in our laboratory is shown in Fig. 2.

\section{Recovery, linearity and MEs}

Recovery and linearity were investigated in sera obtained from six individuals (Supplementary Table 1). The ERs and PE were high and consistent across low-to-high concentration levels. The ER was $60 \%$ for progesterone, and it ranged from 71 to $85 \%$ for the other analytes. There was no significant ion depression or enhancement. The method was linear for all the compounds, except for cortisone and 11DOC. For these two compounds, the highest calibrators of 250 and $25 \mathrm{nmol} / 1$ respectively were slightly underestimated, but had acceptable back-calculated accuracies above $90 \%$.

The variance of the slope constants between different individuals provides a useful index of relative MEs. The CV of the slope constants were $\leq 3 \%$ for all the analytes (Supplementary Table 3, see section on supplementary data given at the end of this article). According to Matuszewski (14), this indicates that the method is robust

$\begin{array}{lr}\text { http://www.endocrineconnections.org } & \text { ๑ } 2013 \text { The authors } \\ \text { DOI: } 10.1530 / \text { EC-13-0023 } & \text { Published by Bioscientifica Ltd }\end{array}$

to intra-individual differences in the serum. On running routine samples, it was observed that the peak areas of the ISs were consistent over a batch of 96 samples with CV typically in the range of $10-20 \%$.

\section{Selectivity}

Potential analytical interference of 48 synthetic and naturally occurring steroid hormones and metabolites (Supplementary Table 2) was investigated. All the analytes were chromatographically separated, except prednisone and prednisolone. Individual injection of these two compounds at $2000 \mathrm{nmol} / \mathrm{l}$ showed that the selected fragment ions of these glucocorticoids did not interfere in the negative ionization mode. In the systematic evaluation of chromatograms from 1000 routine analyses, suspicion of interference was very rare. The quantifier: qualifier peak area ratio was within $\pm 40 \%$ of the expected value for all the analytes of all the samples.

\section{Stability}

Steroid hormones in the serum were stable when stored at $4{ }^{\circ} \mathrm{C}$ or a lower temperature. After storage for up to 25 days at $4{ }^{\circ} \mathrm{C}$ or over 6 months at $-20^{\circ} \mathrm{C}$, all the compounds

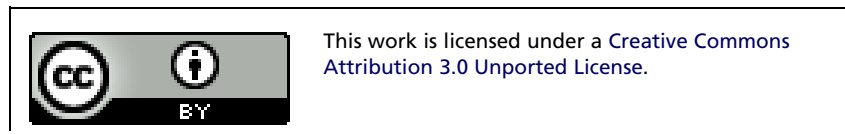


Table 3 Limits of detection (LoDs) and lower limits of quantification (LLoQs).

\begin{tabular}{|c|c|c|c|c|c|c|c|c|c|c|}
\hline & Cortisol & Cortisone & Prednisolone & Prednisone & DXM & 11DOC & Testosterone & $\begin{array}{c}\text { Andro- } \\
\text { stenedione }\end{array}$ & 170нP & $\begin{array}{c}\text { Pro- } \\
\text { gesterone }\end{array}$ \\
\hline LoD (nmol/l) & $<0.1$ & $<0.1$ & $<0.2$ & $<0.2$ & $<0.03$ & $<0.03$ & $<0.01$ & $<0.02$ & $<0.06$ & $<0.06$ \\
\hline LoQ (nmol/l) & 1.95 & 1.58 & 0.49 & 0.97 & 0.061 & 0.098 & 0.018 & 0.122 & 0.244 & 0.122 \\
\hline CV $(\%)$ & 11.4 & 6.7 & 12.3 & 18.3 & 5.4 & 17.3 & 18.8 & 16.9 & 14.2 & 16.9 \\
\hline Accuracy (\%) & 94.6 & 117.9 & 86.0 & 103.6 & 112.0 & 103.5 & 116.2 & 103.8 & 95.9 & 113.4 \\
\hline
\end{tabular}

LoD is defined as a signal-to-noise ratio above 3. LoQ is defined as the lowest level that could be measured with accuracy within $\pm 20 \%$ of the nominal levels and a CV below $20 \%(n=6)$. At the LLoQ, the signal-to-noise ratio was above 10 for all the compounds in all the replicates. DXM, dexamethasone; $11 \mathrm{DOC}$ 11-deoxycortisol; 170HP, 17 $\alpha$-hydroxyprogesterone.

were still measured within $\pm 10 \%$ of their nominal levels with no apparent trends. The compounds were robust to at least five freeze-thaw cycles. Cortisone concentrations were within $\pm 10 \%$ of the nominal levels after $48 \mathrm{~h}$ of storage at ambient temperature; however, for samples containing levels of $50 \mathrm{nmol} /$, concentrations declined to $86 \%$ after $96 \mathrm{~h}$. Similarly, at this time point, the concentrations of samples with prednisone at an initial level of $50 \mathrm{nmol} / \mathrm{l}$ had declined to $84 \%$. Reconstituted samples were stable for at least 4 days at $4{ }^{\circ} \mathrm{C}$.

\section{Application: steroid profiles of women with AD and BDs}

The steroid profiles of patients with $\mathrm{AD}$ and $\mathrm{BDs}$ are reported in Table 4 . The method provided information on the cortisol and cortisone levels of patients on oral hydrocortisone replacement therapy and successfully identified the five patients taking prednisolone (prednisolone $317 \mathrm{nmol} / \mathrm{l}$, range 220-419; prednisone $47.8 \mathrm{nmol} / \mathrm{l}$, range 17.2-86). Nine $\mathrm{AD}$ patients had low levels of $11 \mathrm{DOC}$ (median 0.20; range 0.14-0.32 nmol/l).

Testosterone and androstenedione concentrations were above the LLoQs in all the BDs and most of the women with adrenal insufficiency. The two AD groups of women aged above 60 years and women with premature ovarian failure stood out as in them androgen levels were often not even detectable. Generally, patients with AD exhibited decreasing serum testosterone concentrations with age, and levels were significantly lower in the old group vs the young group $(P=0.0195)$. This was in contrast to the testosterone levels in BDs, where no difference between the old and young groups was observed $(P=1)$. The middle-aged BDs, however, had lower levels than the young group $(P=0.003)$.

Serum androstenedione concentrations also declined with age in women with AD. Androstenedione concentrations in the old group were lower than those in the

http://www.endocrineconnections.org
$\begin{array}{lr}\text { DOI: } 10.1530 / E C-13-0023 & \text { C } 2013 \text { The authors } \\ \end{array}$

middle-aged group $(P<0.00001)$, which again were lower than those of the young group $(P=0.006)$. For BDs, androstenedione concentrations were not significantly different in the middle-aged group and the old group $(P=0.160)$. The young group had higher levels relative to the middle-aged group $(P=0.0002)$ and the old group $(P=0.00007)$.

On comparing women with $\mathrm{AD}$ with $\mathrm{BDs}$, it was found that testosterone levels were significantly lower in all the age-stratified groups (all $P \leq 0.00020$ ). Similarly, androstenedione concentrations were lowest in $\mathrm{AD}$ patients (all $P \leq 0.00005$ ). The levels of $17 \mathrm{OHP}$ in the old groups were lower in $\mathrm{AD}$ patients than in the $\mathrm{BDs}$ $(P<0.00001)$. There were no systematic differences in serum cortisol and cortisone levels between $\mathrm{AD}$ patients and BDs, as expected since the timing of specimen collection was not standardized.

\section{Discussion}

We developed a multiplexed LC-MS/MS assay that targets the work-up of adrenal and gonadal disorders. As demonstrated by the steroid profiles of women with $\mathrm{AD}$, it allows the quantification of very low levels of androgens, as well as measurements of endogenous and synthetic glucocorticoids. The method is automated, requires only $85 \mu \mathrm{l}$ serum and has a chromatographic run time of $6.1 \mathrm{~min}$, which makes it suitable for use in routine endocrine laboratories as well as in research.

The panel of analytes includes the most commonly systemically used synthetic glucocorticoids. This could be particularly useful in a clinical setting as it enables a comprehensive assessment of the patient. For example, the overnight low-dose DXM suppression test is commonly used in the work-up of CS, but its diagnostic specificity of only $80 \%$ is a major drawback (16). The determination of serum DXM could help in identifying

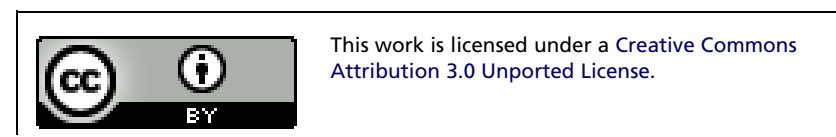



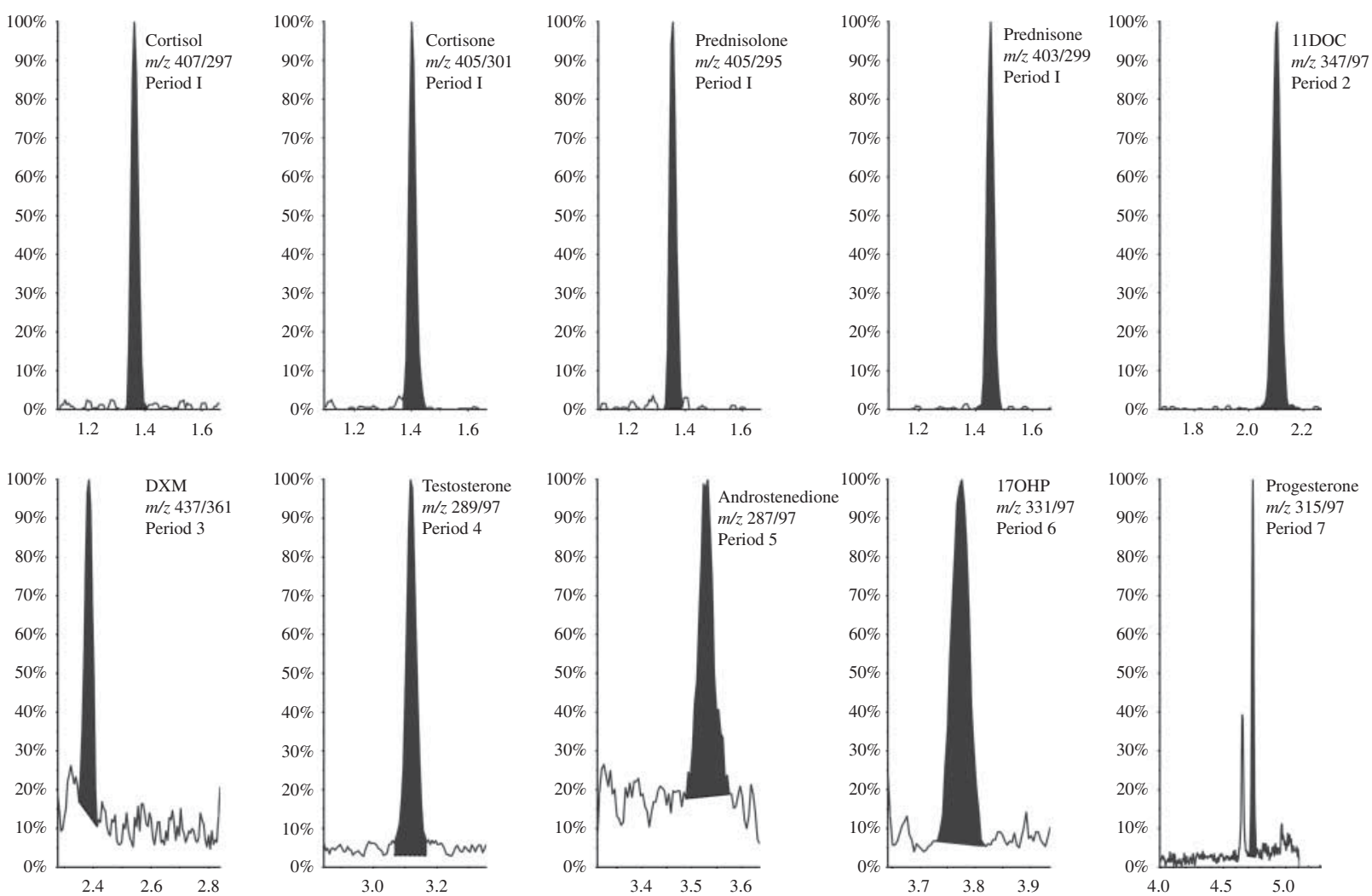

\section{Figure 1}

MS chromatograms of the quantifier mass transition of the lowest working calibrator for each analyte. The nominal concentrations were as follows: $1.95 \mathrm{nmol} / \mathrm{l}$, cortisol; $0.98 \mathrm{nmol} / \mathrm{l}$, cortisone; $0.98 \mathrm{nmol} / \mathrm{l}$, prednisolone; $0.98 \mathrm{nmol} / \mathrm{l}$, prednisone; $0.10 \mathrm{nmol} / \mathrm{l}, 11$-deoxycortisol (11DOC);

patients with false-positive tests due to reduced gastrointestinal DXM absorption or abnormal DXM metabolism. This strategy is indeed suggested by the Endocrine Society (17), but rarely implemented. Moreover, the detection of synthetic glucocorticoid hormones could reveal iatrogenic causes of CS as well as prevent unnecessary investigations in patients with iatrogenic cortisol suppression, both circumstances commonly encountered in the routine laboratory. Moreover, prednisolone and prednisone are commonly used as immunosuppressants and in the treatment of cancer. It is a clinical observation that these drugs show considerable inter-individual variation in dose required for therapeutic effect. Analogously, some patients are more resistant to adverse effects. Therapeutic monitoring of prednisolone and prednisone levels may ultimately optimize clinical response and reduce adverse effects, such as osteoporosis and cardiovascular disease $(18,19,20)$.

$$
\text { http://www.endocrineconnections.org }
$$$$
\text { DOI: 10.1530/EC-13-0023 }
$$

$0.06 \mathrm{nmol} / \mathrm{l}$, dexamethasone (DXM); $0.02 \mathrm{nmol} / \mathrm{l}$, testosterone; $0.12 \mathrm{nmol} / \mathrm{l}$, androstenedione; $0.24 \mathrm{nmol} / \mathrm{l}, 17 \alpha-\mathrm{OH}$-progesterone (17OHP); and $0.24 \mathrm{nmol} / \mathrm{l}$; progesterone. $\mathrm{m} / \mathrm{z}$, mass-to-charge ratio of the ionized compound and fragment.

Our LC-MS/MS assay allows the quantification of serum testosterone in the picomolar range found in women and children, which traditional immunoassays cannot measure reliably (21). We achieved a LLoQ for testosterone of less than one-fifth of that reported by Guo et al. (2) and Ceglarek et al. (3), and functional sensitivity was similar to that of methods employing labour-intensive derivatization procedures to enhance the ionization of androgens $(5,8)$. The LLoQs in the range of $0.02-1.97 \mathrm{nmol} / \mathrm{l}$ are, for most of the analytes, lower than those of previously published LC-MS/MS methods, although our method requires less serum volume $(1,2,3$, $4,5,7,8)$. Combined with simultaneous determination of multiple hormones, low serum volume requirement is an advantage when the specimen is scarce, such as samples from children and population-based biobanks. The low sample volume used also facilitates high-throughput analysis by allowing unattended automation of the

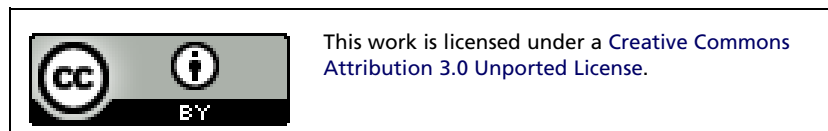



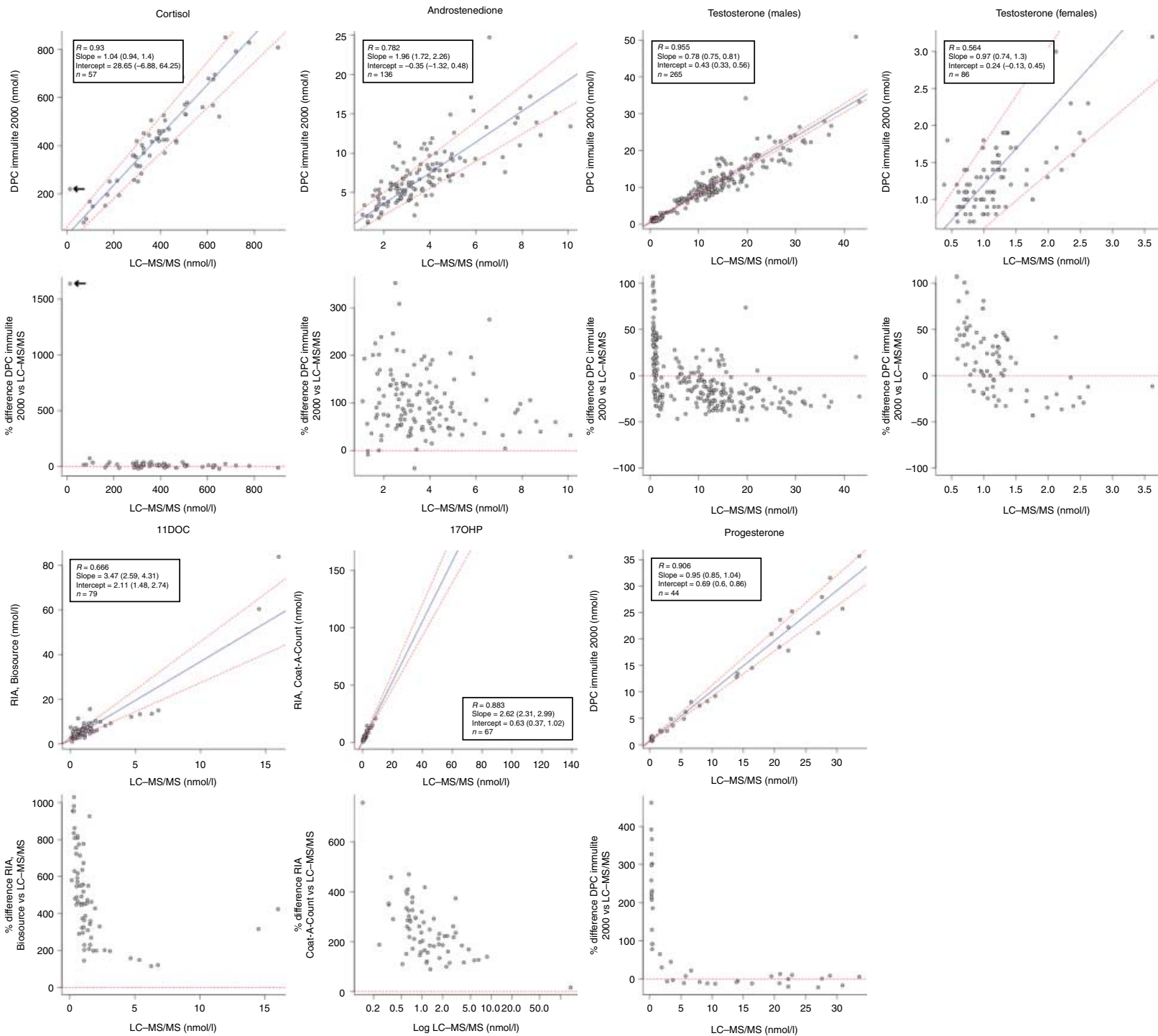

Figure 2

Comparison of the LC-MS/MS method with immunoassays available at the Hormone Laboratory. Statistical analyses were carried out using the Passing-Bablok regression (upper) and Bland-Altman plots (lower).

extraction procedure in a standard 96-well format using a liquid-handling robot. Within an 8-h workday, 288 samples can be prepared, and more than 200 samples per day can be analysed.

When hormones with different chemical properties are assayed simultaneously, there is a balance between obtaining high recoveries for all the compounds and eliminating substances that cause ion suppression or impact method ruggedness. Overall, extraction with ethyl acetate:hexane yielded high recoveries without significant ion suppression or enhancement. The clean extracts
Arrows in cortisol plots denote a patient put on prednisolone therapy in whom the immunoassay reported falsely elevated cortisol levels ( 220 vs $12 \mathrm{nmol} / \mathrm{l}$ ).

contributed to the long lifetime of the analytical column, which typically withstood thousands of injections.

Although MS is a highly specific analytical detector, it is necessary to chromatographically separate the steroid analytes from isobaric isomers and other interfering compounds. We found that the Zorbax RRHD C18 column performed well for both glucocorticoids and androgens. A reversed-phase column with phenyl-bonded stationary phase may better separate cortisol, cortisone, prednisolone and prednisone (22), but is incapable of resolving androgens from interfering compounds. Because the

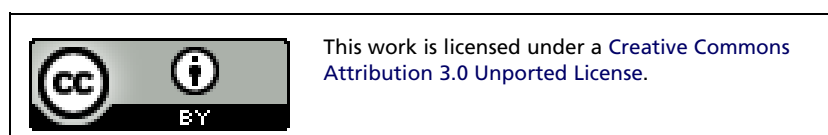




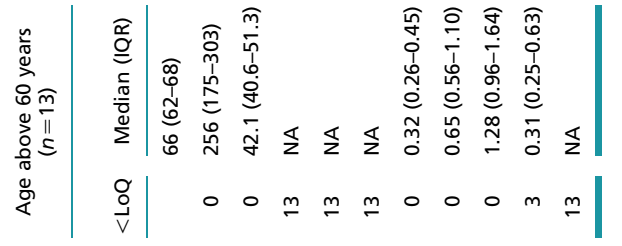

glucocorticoids formed specific adducts with formic acid in the negative ionization mode, the co-elution of prednisone and prednisolone was without significant cross-interference.

The increasing sensitivity of the latest generation of MS instruments has increased awareness and concern for isobaric interferences, in particular, in the picomolar range. Monitoring two mass transitions (i.e. collision fragments) adds another layer of specificity as an unexpected deviation of the ratio of the quantifier to qualifier peak areas should raise suspicion of interference $(23,24)$. Although monitoring two mass transitions reduces scan time and thus sensitivity and LLoQ, this strategy has been recommended (25) or advised as mandatory (26) for steroid analysis. Our assay monitors two mass transitions, which we believe is an important improvement compared with other multisteroid methods $(2,3,4,5,6)$.

Inter-individual differences in serum composition could potentially impact measurements. For example, the ER of steroids in the serum may vary with the amount of binding proteins and lipids. An isotopic analogue of the analyte is commonly used as an IS to compensate for such loss. Nevertheless, it is still possible that the binding of the IS to various components in the serum is not in perfect equilibrium with the analyte. Another concern, particularly relevant to the increased resolution offered by ultra-highpressure LC, is that the ionization efficiency of the analyte and IS may differ as they do not always co-elute exactly (27). Therefore, a strength of our method is the comprehensive validation of relative MEs, which often are not investigated at all $(1,2)$. The consistent results obtained when calibration curves were prepared for sera collected from different individuals indicate that the assay is robust to interindividual differences in serum composition.

The clinical usefulness of the method was demonstrated by comparing steroid profiles of women with $\mathrm{AD}$ with those of BDs. The measurements of endogenous and synthetic glucocorticoids indicate the potential of the method to assess patients on glucocorticoid therapy. The five patients on prednisolone replacement therapy were identified by the detection and quantification of prednisone and prednisolone.

Herein, we report data on androgens in women with $\mathrm{AD}$. To our knowledge, this study is the first to investigate testosterone and androstenedione concentrations in a large cohort of women with adrenal insufficiency using highly specific MS. To differentiate between premenopausal and postmenopausal status, we stratified the study subjects into young ( $<40$ years), middle-aged (40-60 years) and old ( $>60$ years) groups. The middle-aged

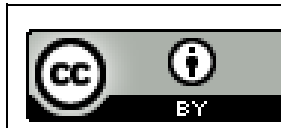


group is expected to comprise a mixture of fertile and postmenopausal women. We found that in $\mathrm{AD}$ women aged below 40 years, androstenedione and testosterone concentrations were roughly $50 \%$ of those found in BDs. This is in line with studies indicating that androgens originate from the adrenal glands and ovaries at about equal ratios in fertile healthy females (28). An interesting finding is the very low androgen levels in women with $\mathrm{AD}$ aged above 60 years, as opposed to the levels in healthy females of comparable age. This may suggest that postmenopausal women with $\mathrm{AD}$, in particular, are deficient of androgens. It also raises the question as to why the postmenopausal ovary in AD ceases to secrete androgens. Notably, there has long been a controversy whether the postmenopausal ovary indeed is a major androgen-producing organ $(29,30)$. A reasonable interpretation of our data could be that the premenopausal ovary is capable of de novo androgen synthesis, while the postmenopausal ovary depends on adrenal DHEA/S as the substrate to produce testosterone and androstenedione. This would explain the low androgen levels found in postmenopausal women with $\mathrm{AD}$. Moreover, this may also explain some of the discrepant results of DHEA replacement in $\operatorname{AD}(15,31,32,33)$ because the study populations investigated differ in gender, menopausal status and autoimmune ovarian failure. Conceivably, DHEA replacement therapy may be more effective in the postmenopausal AD women without autoimmune ovarian damage.

Alteration in binding globulin, for example, due to the use of oral contraceptives, could potentially influence the unbound levels of androgen in the serum. We did not measure SHBG levels, which is a limitation of our study. If SHBG levels were considerably lower in women with $\mathrm{AD}$ than in the BDs, one would expect the free fractions levels in $\mathrm{AD}$ to be increased relative to total hormone levels. However, previous reports indicate that SHBG levels in adrenal failure are in the middle-to-upper normal range, $65-90 \mathrm{nmol} / \mathrm{l}$ $(34,35,36)$. Moreover, the postmenopausal women in our study were not on oral contraceptives. We, therefore, believe that the very low levels of total serum testosterone and androstenedione in women with $\mathrm{AD}$ indicate reduced bioactive androgens available to target tissues.

In conclusion, we developed a simple, automated, fast and highly specific LC-MS/MS assay that quantifies endogenous androgens and glucocorticoids, together with common synthetic glucocorticoids used in diagnosis and treatment. The method is highly sensitive and allows the measurement of androgens in women and children. The abilities of the method were illustrated by profiling steroid hormones in a large cohort of females with and without $\mathrm{AD}$. The levels of androgens were lowest in women with $\mathrm{AD}$ across all age groups, but particularly in those aged above 60 years. This may suggest that androgen synthesis in the postmenopausal ovary depends on adrenal DHEA/S as the substrate.

\section{Supplementary data}

This is linked to the online version of the paper at http://dx.doi.org/10.1530/ EC-13-0023.

\section{Declaration of interest}

The authors declare that there is no conflict of interest that could be perceived as prejudicing the impartiality of the research reported.

\section{Funding}

The study was supported by grants from The Regional Health Authorities of Western Norway and the European Union (FP7 Euradrenal, grant no. 201167).

\section{Acknowledgements}

We thank Franziska Randers, Otto Borholm, Øyvind S Holen and Ole-Thomas $S$ Andersen for their excellent technical assistance and interesting discussions.

\section{References}

1 Guo T, Chan M \& Soldin SJ. Steroid profiles using liquid chromatographytandem mass spectrometry with atmospheric pressure photoionization source. Archives of Pathology \& Laboratory Medicine 2004128 469-475.

2 Guo T, Taylor RL, Singh RJ \& Soldin SJ. Simultaneous determination of 12 steroids by isotope dilution liquid chromatography-photospray ionization tandem mass spectrometry. Clinica Chimica Acta 2006372 76-82. (doi:10.1016/j.cca.2006.03.034)

3 Ceglarek U, Kortz L, Leichtle A, Fiedler GM, Kratzsch J \& Thiery J. Rapid quantification of steroid patterns in human serum by on-line solid phase extraction combined with liquid chromatography-triple quadrupole linear ion trap mass spectrometry. Clinica Chimica Acta 2009401 114-118. (doi:10.1016/j.cca.2008.11.022)

4 Harwood DT \& Handelsman DJ. Development and validation of a sensitive liquid chromatography-tandem mass spectrometry assay to simultaneously measure androgens and estrogens in serum without derivatization. Clinica Chimica Acta 2009409 78-84. (doi:10.1016/ j.cca.2009.09.003)

5 Keski-Rahkonen P, Huhtinen K, Poutanen M \& Auriola S. Fast and sensitive liquid chromatography-mass spectrometry assay for seven androgenic and progestagenic steroids in human serum. Journal of Steroid Biochemistry and Molecular Biology 2011127 396-404. (doi:10.1016/j.jsbmb.2011.06.006)

6 Moal V, Mathieu E, Reynier P, Malthièry Y \& Gallois Y. Low serum testosterone assayed by liquid chromatography-tandem mass spectrometry. Comparison with five immunoassay techniques. Clinica Chimica Acta 2007386 12-19. (doi:10.1016/j.cca.2007.07.013)

7 Carvalho VM, Nakamura OH \& Vieira JGH. Simultaneous quantitation of seven endogenous C-21 adrenal steroids by liquid chromatography tandem mass spectrometry in human serum. Journal of Chromatography. B, Analytical Technologies in the Biomedical and Life Sciences $2008 \mathbf{8 7 2}$ 154-161. (doi:10.1016/j.jchromb.2008.07.035)

8 Kushnir MM, Blamires T, Rockwood AL, Roberts WL, Yue B, Erdogan E, Bunker AM \& Meikle AW. Liquid chromatography-tandem mass

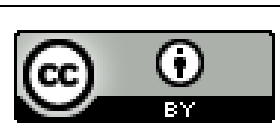


spectrometry assay for androstenedione, dehydroepiandrosterone, and testosterone with pediatric and adult reference intervals. Clinical Chemistry 201056 1138-1147. (doi:10.1373/clinchem.2010.143222)

9 Hempen C, Elfering S, Mulder AHL, van den Bergh FAJTM \& Maatman RGHJ. Dexamethasone suppression test: development of a method for simultaneous determination of cortisol and dexamethasone in human plasma by liquid chromatography/tandem mass spectrometry. Annals of Clinical Biochemistry 201249 170-176. (doi:10.1258/acb.2011.011004)

10 Asvold BO, Grill V, Thorstensen K \& Bjorgaas MR. Association between posttest dexamethasone and cortisol concentrations in the $1 \mathrm{mg}$ overnight dexamethasone suppression test. Endocrine Connections 2012 1 62-67. (doi:10.1530/EC-12-0047)

11 Laverdière I, Caron P, Couture F, Lévesque E \& Guillemette C. A liquid chromatography-tandem mass spectrometry (LC-MS/MS) method for monitoring drug exposure in hematopoietic stem cell transplant recipients. Journal of Chromatography. B, Analytical Technologies in the Biomedical and Life Sciences 2012 885-886 131-137. (doi:10.1016/ j.jchromb.2011.12.029)

12 Sæves I, Line P-D \& Bergan S. The pharmacokinetics of prednisolone and prednisone in adult liver transplant recipients early after transplantation. Therapeutic Drug Monitoring 201234 452-459. (doi:10.1097/FTD.0b013e31825ee3f8)

13 Matuszewski BK, Constanzer ML \& Chavez-Eng CM. Strategies for the assessment of matrix effect in quantitative bioanalytical methods based on HPLC-MS/MS. Analytical Chemistry 200375 3019-3030. (doi:10.1021/ac020361s)

14 Matuszewski BK. Standard line slopes as a measure of a relative matrix effect in quantitative HPLC-MS bioanalysis. Journal of Chromatography. B, Analytical Technologies in the Biomedical and Life Sciences 2006830 293-300. (doi:10.1016/j.jchromb.2005.11.009)

15 Erichsen MM, Husebye ES, Michelsen TM, Dahl AA \& Løvås K. Sexuality and fertility in women with Addison's disease. Journal of Clinical Endocrinology and Metabolism 201095 4354-4360. (doi:10.1210/jc.2010-0445)

16 Findling JW, Raff H \& Aron DC. The low-dose dexamethasone suppression test: a reevaluation in patients with Cushing's syndrome. Journal of Clinical Endocrinology and Metabolism 200489 1222-1226. (doi:10.1210/jc.2003-030207)

17 Nieman LK, Biller BMK, Findling JW, Newell-Price J, Savage MO, Stewart PM \& Montori VM. The diagnosis of Cushing's syndrome: an Endocrine Society Clinical Practice Guideline. Journal of Clinical Endocrinology and Metabolism 200893 1526-1540. (doi:10.1210/jc.2008-0125)

18 Morton JM, Williamson S, Kear LM, McWhinney BC, Potter J \& Glanville AR. Therapeutic drug monitoring of prednisolone after lung transplantation. Journal of Heart and Lung Transplantation 200625 557-563. (doi:10.1016/j.healun.2005.11.460)

19 Hill MR, Szefler SJ, Ball BD, Bartoszek M \& Brenner AM. Monitoring glucocorticoid therapy: a pharmacokinetic approach. Clinical Pharmacology and Therapeutics 199048 390-398. (doi:10.1038/clpt.1990.167)

20 Potter JM, McWhinney BC, Sampson L \& Hickman PE. Area-underthe-curve monitoring of prednisolone for dose optimization in a stable renal transplant population. Therapeutic Drug Monitoring 200426 408-414. (doi:10.1097/00007691-200408000-00011)

21 Taieb J, Mathian B, Millot F, Patricot M-C, Mathieu E, Queyrel N, Lacroix I, Somma-Delpero C \& Boudou P. Testosterone measured by 10 immunoassays and by isotope-dilution gas chromatography-mass spectrometry in sera from 116 men, women, and children. Clinical Chemistry 200349 1381-1395. (doi:10.1373/49.8.1381)

22 Ionita IA, Fast DM \& Akhlaghi F. Development of a sensitive and selective method for the quantitative analysis of cortisol, cortisone, prednisolone and prednisone in human plasma. Journal of
Chromatography. B, Analytical Technologies in the Biomedical and Life Sciences 2009877 765-772. (doi:10.1016/j.jchromb.2009.02.019)

23 Kushnir MM, Rockwood AL, Nelson GJ, Yue B \& Urry FM. Assessing analytical specificity in quantitative analysis using tandem mass spectrometry. Clinical Biochemistry 200538 319-327. (doi:10.1016/ j.clinbiochem.2004.12.003)

24 Vogeser M \& Seger C. Pitfalls associated with the use of liquid chromatography-tandem mass spectrometry in the clinical laboratory. Clinical Chemistry 201056 1234-1244. (doi:10.1373/clinchem.2009.138602)

25 Kushnir MM, Rockwood AL \& Bergquist J. Liquid chromatographytandem mass spectrometry applications in endocrinology. Mass Spectrometry Reviews 201029 480-502. (doi:10.1002/mas.20264)

26 Carvalho VM. The coming of age of liquid chromatography coupled to tandem mass spectrometry in the endocrinology laboratory. Journal of Chromatography. B, Analytical Technologies in the Biomedical and Life Sciences 2012 883-884 50-58. (doi:10.1016/j.jchromb.2011.08.027)

27 Wang S, Cyronak M \& Yang E. Does a stable isotopically labeled internal standard always correct analyte response? A matrix effect study on a LC/MS/MS method for the determination of carvedilol enantiomers in human plasma Journal of Pharmaceutical and Biomedical Analysis 200743 701-707. (doi:10.1016/j.jpba.2006.08.010)

28 Burger HG. Androgen production in women. Fertility and Sterility 2002 77 (Suppl 4) S3-S5. (doi:10.1016/S0015-0282(02)02985-0)

29 Fogle RH, Stanczyk FZ, Zhang X \& Paulson RJ. Ovarian androgen production in postmenopausal women. Journal of Clinical Endocrinology and Metabolism 200792 3040-3043. (doi:10.1210/jc.2007-0581)

30 Couzinet B, Meduri G, Lecce MG, Young J, Brailly S, Loosfelt H, Milgrom E \& Schaison G. The postmenopausal ovary is not a major androgen-producing gland. Journal of Clinical Endocrinology and Metabolism 200186 5060-5066. (doi:10.1210/jc.86.10.5060)

31 Arlt W, Callies F, van Vlijmen JC, Koehler I, Reincke M, Bidlingmaier M, Huebler D, Oettel M, Ernst M, Schulte HM et al. Dehydroepiandrosterone replacement in women with adrenal insufficiency. New England Journal of Medicine 1999341 1013-1020. (doi:10.1056/ NEJM199909303411401)

32 Løvås K, Gebre-Medhin G, Trovik TS, Fougner KJ, Uhlving S, Nedrebø BG, Myking OL, Kämpe O \& Husebye ES. Replacement of dehydroepiandrosterone in adrenal failure: no benefit for subjective health status and sexuality in a 9-month, randomized, parallel group clinical trial. Journal of Clinical Endocrinology and Metabolism $2003 \mathbf{8 8}$ 1112-1118. (doi:10.1210/jc.2002-020769)

33 Alkatib AA, Cosma M, Elamin MB, Erickson D, Swiglo BA, Erwin PJ \& Montori VM. A systematic review and meta-analysis of randomized placebo-controlled trials of DHEA treatment effects on quality of life in women with adrenal insufficiency. Journal of Clinical Endocrinology and Metabolism 200994 3676-3681. (doi:10.1210/jc.2009-0672)

34 Gebre-Medhin G, Husebye ES, Mallmin H, Helström L, Berne C, Karlsson FA \& Kämpe O. Oral dehydroepiandrosterone (DHEA) replacement therapy in women with Addison's disease. Clinical Endocrinology 200052 775-780. (doi:10.1046/j.1365-2265.2000.01017.x)

35 Gurnell EM, Hunt PJ, Curran SE, Conway CL, Pullenayegum EM, Huppert FA, Compston JE, Herbert J \& Chatterjee VKK. Long-term DHEA replacement in primary adrenal insufficiency: a randomized, controlled trial. Journal of Clinical Endocrinology and Metabolism 200893 400-409. (doi:10.1210/jc.2007-1134)

36 Christiansen JJ, Bruun JM, Christiansen JS, Jørgensen JO \& Gravholt CH. Long-term DHEA substitution in female adrenocortical failure, body composition, muscle function, and bone metabolism: a randomized trial. European Journal of Endocrinology 2011165 293-300. (doi:10.1530/EJE-11-0289) http://www.endocrineconnections.org

DOI: 10.1530/EC-13-0023 (c) 2013 The authors Published by Bioscientifica Ltd
Received in final form 7 June 2013

Accepted 12 June 2013
This work is licensed under a Creative Commons Attribution 3.0 Unported License. 